colonización española en el Estrecho de Magallanes. An Hist Med 2013 (Inédito, aceptado para publicación).

3.- Domínguez R. La pista médica del desastre de la expedición de Sarmiento de Gamboa al Estrecho de Magallanes.

Magallania (Chile) 2011; 39 (2): 5-13.

4.- Martinic M. Desde la prehistoria hasta el tiempo del contacto con los foráneos. En: la medicina en Magallanes. Noticias y consideraciones para su historia. Ed. La Prensa Austral, $2^{\mathrm{a}}$ Ed. 2010.

5.- Vieira M. La pediatría de los Selknam. Rev Chil Pediatr 2006; 77 (3): 237-8.

6.- Cooper J. Analytical and critical bibliography of the tribes of Tierra del Fuego and adjacent territory. Smithsonian Institution. Bureau of American Ethnology, Bulletin 63. Washington Government Printing Office, 1917.

7.- Gusinde M. Los indios de la tierra del fuego. Centro de Etnología Americana de Buenos Aires, Ed. 1982.

8.- Vera R. La colonia de Magallanes y Tierra del Fuego (1843-1897). Santiago de Chile, Imprenta de la Gaceta, Ed. 1897.

9.- Martinic M. La salud pública en la colonia de Magallanes (1843-1894). En: la medicina en Magallanes. Noticias y consideraciones para su historia. Ed. La Prensa Austral, $2^{\mathrm{a}}$ Ed. 2010.

\title{
Anecdotario Infectológico
}

\section{Zoonosis en el hogar}

\section{A zoonosis outbreak at home}

U na niña de 2 años 5 meses consultó por presentar los 4 días previos deposiciones semilíquidas y el día anterior fiebre, deposiciones con moco, sangre, y dolor abdominal. En la evaluación médica no hubo mayores hallazgos semiológicos. Solicitados exámenes generales de sangre y deposiciones, se le indicó medidas dietéticas y probióticos con el diagnostico de síndrome disentérico. Su evolución fue rápidamente favorable.

Días más tarde se obtuvo informe del coprocultivo el que describía desarrollo de Salmonella Poona (Grupo G), diagnóstico certificado por el I.S.P., Laboratorio Nacional de Referencia. Reevaluada la paciente se encontraba asintomática, como también sus padres y hermano. Se solicitó un nuevo coprocultivo de la paciente y en su hermano, resultando ambos negativos.

Indagando sobre la existencia de mascotas en el hogar, la madre recordó la llegada a casa de dos pequeñas tortugas acuáticas, pocos días antes del inicio del cuadro febril en su hija. La breve vida de las tortugas terminó cuando el perro de la casa las devoró en un momento de descuido. Un par de días después el perro enfermó brevemente, presentando deposiciones semilíquidas con sangre lo cual fue atribuido por los padres a la ingesta de la caparazón de las tortugas. Antes de ser llevado a un veterinario el perro mejoró espontáneamente y no fue estudiado microbiológicamente.

Contribución de Guillermo Vargas Brugues

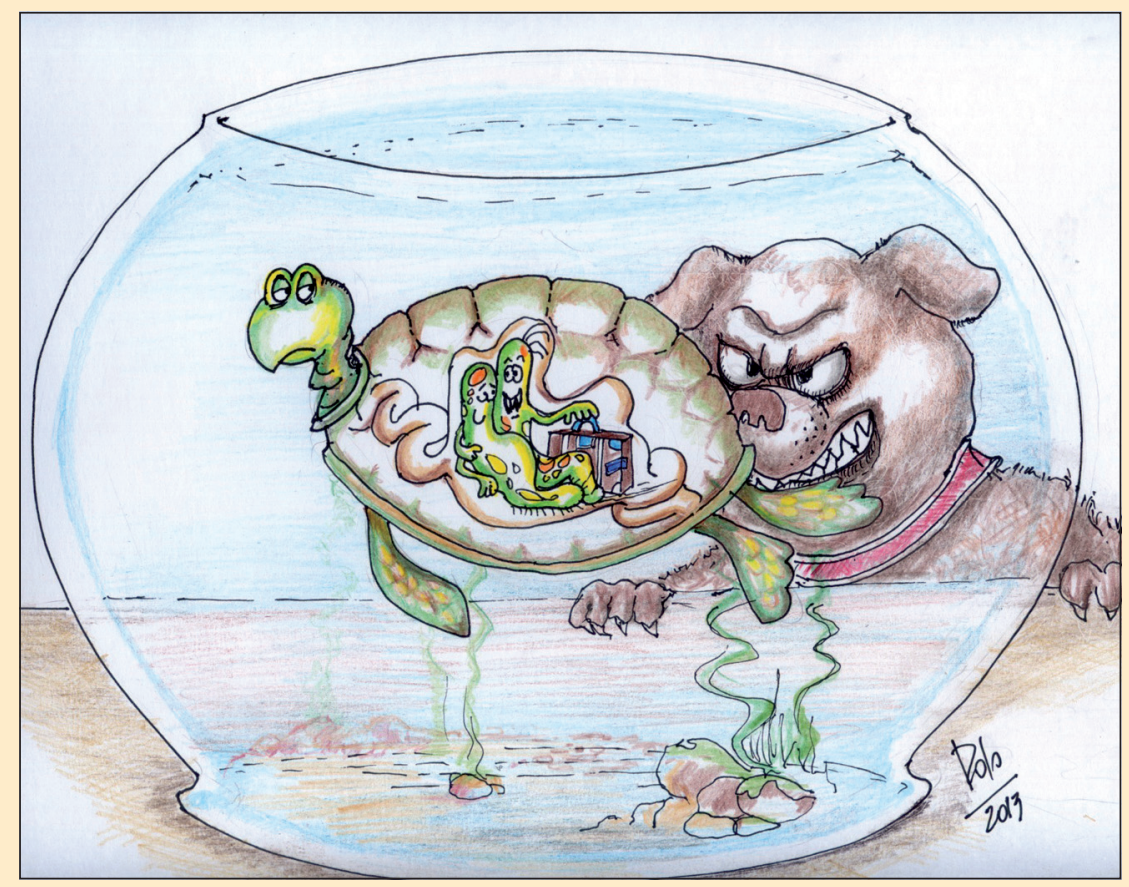

